\title{
Effect of $\mathrm{CaCO}_{3}$ Additive on The Warpage of Injection Molding Part
}

\author{
Pham Son Minh ${ }^{1, *}$, Phan The Nhan ${ }^{2}$ \\ ${ }^{1}$ University of Technical Education, Ho Chi Minh City, Vietnam \\ ${ }^{2}$ Ho Chi Minh Vocational College of Technology, HCM City, Vietnam \\ *Corresponding Author: minhps@hcmute.edu.vn
}

Copyright (C) 2014 Horizon Research Publishing All rights reserved.

\begin{abstract}
In injection molding process, improving the part quality by reducing the warpage is an issue, especially with the thin-walled product. In this paper, the injection molding process was applied to a rectangular plate of 150 $\mathrm{mm} \times 30 \mathrm{~mm}$. The part thickness was varied from $1.0 \mathrm{~mm}$ to $2.5 \mathrm{~mm}$. Three types of material as polypropylene (PP), acrylonitrin butadiene styrene (ABS), and polyvinyl chloride (PVC) were selected for observing the influence of volume shrinkage ratio on the warpage. Then, different weight ratios of $\mathrm{CaCO}_{3}(10 \%, 20 \%, 30 \%$, and $40 \%)$ additive were mixed with the PP material and then, the mixture was molded. The result shows that the volume shrinkage ratio of plastic material has a strong influence on the part warpage with the thickness of $1.0 \mathrm{~mm}, 1.5 \mathrm{~mm}$, and $2.0 \mathrm{~mm}$. However, with the thickness of $2.5 \mathrm{~mm}$, the different warpage under three types of plastic is not strongly. With the $\mathrm{CaCO}_{3}$, the result shows that the more the $\mathrm{CaCO}_{3}$ additive, the lesser is the part warped. However, with a thickness of $2.5 \mathrm{~mm}$, the $\mathrm{CaCO}_{3}$ has a negative influence on the warpage. In addition, this research was achieved by both simulation and experiment. The comparison shows that the simulation result and experiment result agree well.
\end{abstract}

Keywords Injection Molding, Warpage, Shrinkage, Plastic Additive

\section{Introduction}

Nowadays, plastic materials have a wide application in industry and in common products. Significant advantages of plastic could be listed as light weight, resistance to corrosion, ease of manufacturing, and shaping. Based on these properties, plastic material can be used in industry in fields such as electronic, mechanical, aerospace and aviation. In the trend of lighter, smaller, and thinner product, the plastic part is increasingly difficult to manufacture. Therefore, a lot of researches had been done with the aim of improving the accuracy of plastic processing.

In the field of plastic processing, injection molding is one of the most popular process. In injection molding process, the raw material is heated to the melt stage, then, the melt material is pressed into a closed cavity for shaping. After that, the melt volume is cooled down by the heat transfer between the melt and the mold material. When the part reaches the ejection temperature, two-half molds open, and the plastic part is ejected from the mold. By this process, the plastic product is manufactured from the raw material. However, for satisfying the higher requirement from the customer, the injection molding has to be researched to improve the part qualities such as accuracy, surface glosses, and strength. One of the main requirements is the part warpage, which must be reduced to increase the accuracy of product.

For researching about the part warpage in injection molding, the C-Mold software was applied to observe the case of intelligent materials processing [1]. With the researches of optimization [2 - 4], the ANOVA methods and Taguchi optimization technique were used to decide the injection molding parameters. This research shows that the packing pressure is the most important element, which effect on the part warpage. In contrast, the structure of the mold is also assumed to affect the shrinkage and the warpage of the part [5]. The result of these papers shows that the gate location has a strong influence on the warpage. By design the gate location that has a shorter flow length, will undergo less warpage [6]. In addition, the other study found out that the barrel temperature [7], mold temperature [8], and melt temperature $[9,10]$ also have the influence on the warpage, especially with the thin-walled plastic product.

In contrast, the additive material method was presented as a solution for increasing the part hardness; therefore, the shrinkage and warpage also reduce. Yu et al. [11] and Song et al. [12] have done numerical analysis on a thin-walled part which has a fiber reinforced thermoplastic material by the Moldflow software. These papers had been done with different fibers size and ratios. The result shows that a higher fiber ratio with longer fiber length has a positive effect on the part warpage. In other paper, magnesium was added into $\mathrm{ABS}$ and $\mathrm{ABS} / \mathrm{PC}$ (polycarbonate) material [13 - 15]. In this research, the effect of magnesium shows an improvement on the warpage; however, the ratio of magnesium still needs a 
more detailed research. Leroy et al. [16] and Zhil'tsova [17] have conducted studies for determining the most appropriate condition for a thin-walled part. To consider the shrinkage and warpage problems, a cell phone was selected as a research model, and mold temperature, melt temperature, packing pressure, and injection speed were taken as the injection parameters. As a result of experiments, packing pressure was found to be the most influential parameter.

According to above researches, with the same plastic material, there are many elements which effect on the part warpage, as well as part quality. So, in this paper, for observing the effect of volume shrinkage on the part warpage, three types of plastic material were used. The plastic materials are $\mathrm{PP}, \mathrm{PVC}$, and $\mathrm{ABS}$. After that, the $\mathrm{CaCO}_{3}$ will be mixed with PP material with the ratio change from $0 \%$ to $40 \%$. In addition, because the thickness of plastic product is often varied from $1.0 \mathrm{~mm}$ to $2.5 \mathrm{~mm}$, hence, four types of part thickness were researched with different material and $\mathrm{CaCO}_{3}$ ratio. In this paper, the Moldflow software will be applied for simulation. During experimentation, the injection molding system was built with the same parameters as in simulation. For finding the effect of material, part thickness, and $\mathrm{CaCO}_{3}$ ratio on the part thickness, the simulation and experiment result will be collected and compared.

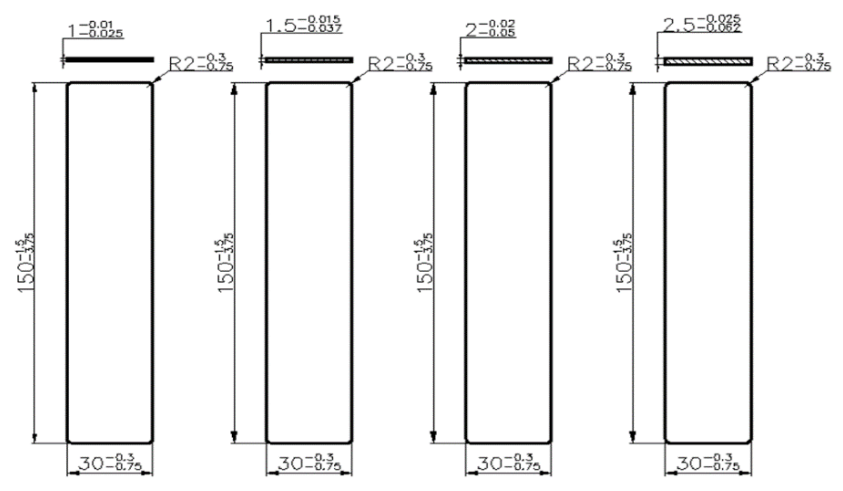

Figure 1. Model dimension

\section{Simulation and Experiment Work}

In this paper, the warpage of injection molding product was researched under different plastic materials, part thicknesses, and weight ratios of $\mathrm{CaCO}_{3}$ additive. In the process, firstly, research was conducted on three types of plastic materials, i.e., PP, ABS, and PVC by simulation and experimentation. After that, the $\mathrm{CaCO}_{3}$ was mixed with PP material under four weight ratios with the value of $10 \%$, $20 \%, 30 \%$, and $40 \%$. In all the cases of this research, the part dimension was $150 \mathrm{~mm} \times 30$, and the part thickness varied from $1.0 \mathrm{~mm}$ to $2.5 \mathrm{~mm}$, as shown in Figure 1. The warpage was calculated by simulation; then, the result was collected for comparison and discussion. The meshing model used in simulation is show in Figure 2. All simulation cases were studied by the Moldflow software with a total number of 105,562 elements. In simulation, the melt cavity, the runner system, and the cooling system were built. The 1-D element type was applied to the cooling system, and the tetra element type was used for the other part as melt cavity and runner system. In addition, for each case of simulation, only one cavity is modeled and studied. This helped to increase the accuracy of numerical study and reduce the simulation time.

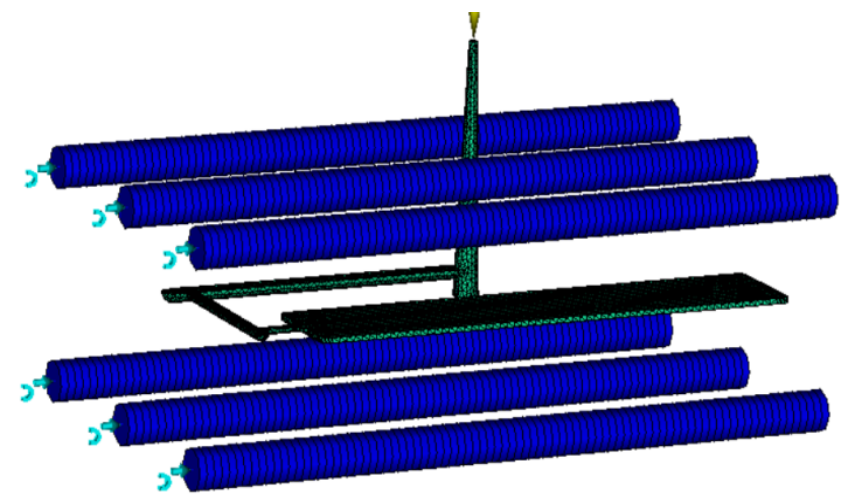

Figure 2. Simulation model

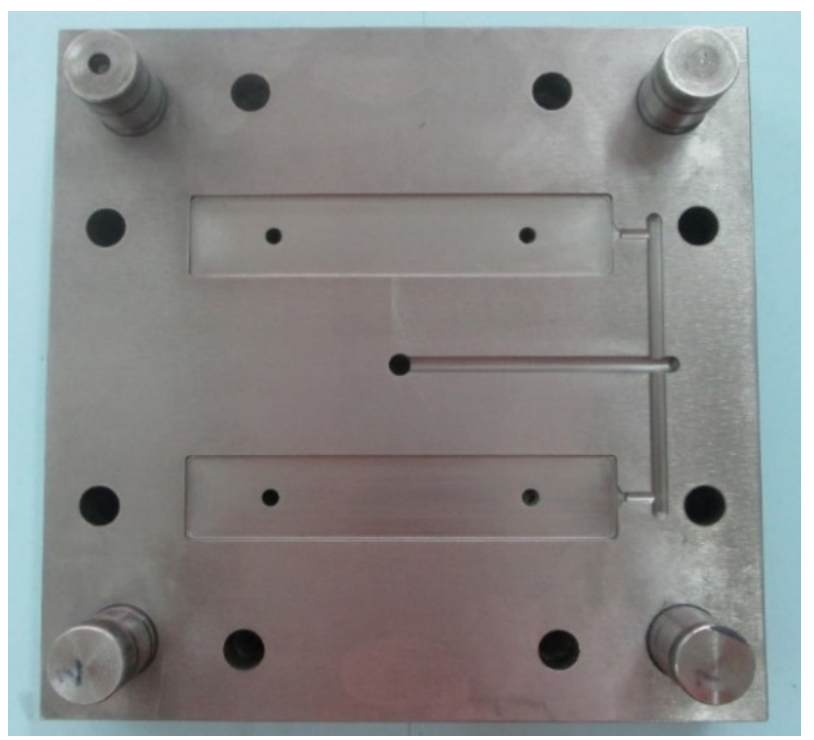

Figure 3. Cavity plate for experimentation.

By experimentation, a mold structure was built by the stainless steel 420 . The cavity plate was manufactured with two cavities, as shown in Figure 3. Each cavity was used for one type of the part thickness. Therefore, in this research, with four values of the part thickness, two cavity plates were made. In the molding process, one side of cavity was prevented at the runner. Therefore, by one injection molding cycle, only one cavity was filled. This solution fits with the simulation model as shown in Figure 2. For measuring the part warpage, each case was operated with about 20 cycles. Moreover, when the system was stable, 10 samples were collected. After that, each sample was measured, as in Figure 4. The average value was calculated and used for comparison with other cases. 


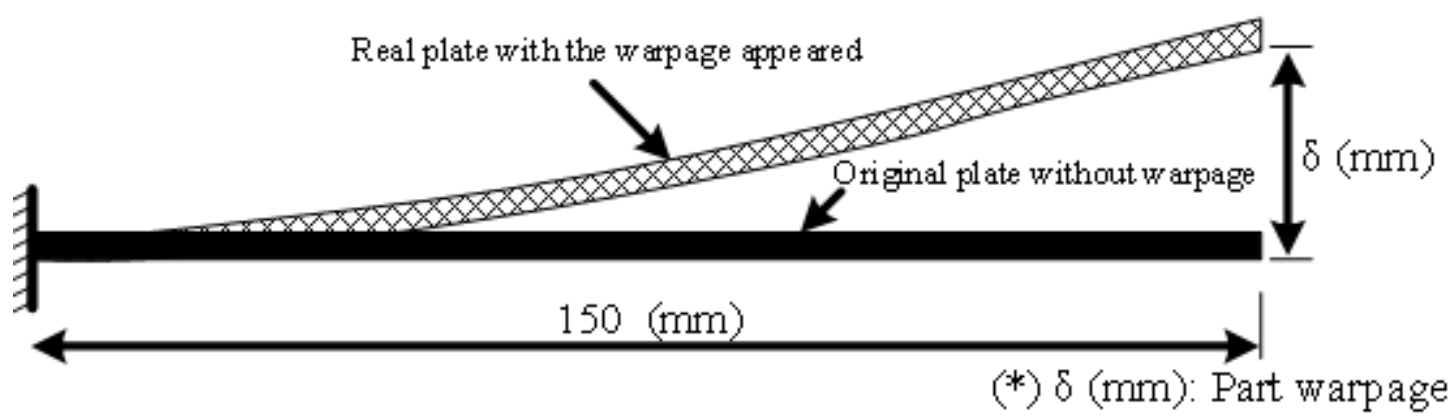

Figure 4. Warpage measurement

Table 1. Materials and Molding parameter [22]

\begin{tabular}{|c|c|c|}
\hline \multirow{4}{*}{ General parameters } & Cooling time & $15 \mathrm{~s}$ \\
\hline & Filling time & $1 \mathrm{~s}$ \\
\hline & Packing time & $10 \mathrm{~s}$ \\
\hline & Packing pressure & $80 \%$ \\
\hline \multirow{4}{*}{ Polypropylene (PP) } & Mold temperature $\left(20^{\circ} \mathrm{C} \rightarrow 80^{\circ} \mathrm{C}\right)$ & $40{ }^{\circ} \mathrm{C}$ \\
\hline & Melt temperature $\left(200^{\circ} \mathrm{C} \rightarrow 280^{\circ} \mathrm{C}\right)$ & $200^{\circ} \mathrm{C}$ \\
\hline & Density & $0.92889 \mathrm{~g} / \mathrm{cm}^{3}$ \\
\hline & Volume shrinkage & $2.5 \%$ \\
\hline \multirow{4}{*}{$\begin{array}{l}\text { Polyvinyl chloride } \\
\text { (PVC) }\end{array}$} & Mold temperature $\left(20^{\circ} \mathrm{C} \rightarrow 40^{\circ} \mathrm{C}\right)$ & $30{ }^{\circ} \mathrm{C}$ \\
\hline & Melt temperature $\left(150^{\circ} \mathrm{C} \rightarrow 250^{\circ} \mathrm{C}\right)$ & $200^{\circ} \mathrm{C}$ \\
\hline & Density & $1.1981 \mathrm{~g} / \mathrm{cm}^{3}$ \\
\hline & Volume shrinkage & $0.4 \%$ \\
\hline \multirow{4}{*}{$\begin{array}{l}\text { Acrylonitrin butadiene } \\
\text { styrene (ABS) }\end{array}$} & Mold temperature $\left(25^{\circ} \mathrm{C} \rightarrow 80^{\circ} \mathrm{C}\right)$ & $52{ }^{\circ} \mathrm{C}$ \\
\hline & Melt temperature $\left(200^{\circ} \mathrm{C} \rightarrow 280^{\circ} \mathrm{C}\right)$ & $240^{\circ} \mathrm{C}$ \\
\hline & Density & $1.0541 \mathrm{~g} / \mathrm{cm}^{3}$ \\
\hline & Volume shrinkage & $0.5 \%$ \\
\hline
\end{tabular}

\section{Results and Discussions}

\subsection{Effect of Volume Shrinkage on the Part Warpage with Different Part Thickness}

In this paper, the part thickness is varied from $1.0 \mathrm{~mm}$, $1.5 \mathrm{~mm}, 2.0 \mathrm{~mm}$, and $2.5 \mathrm{~mm}$ and was used for both experimentation and simulation. In addition, to verify the effect of volume shrinkage of material on the part warpage, three types of materials were applied. They are PP, PVC, and ABS. The properties and molding parameters of these materials are shown in Table 1. According to these data, the $\mathrm{PP}$ has the volume shrinkage of $2.5 \%$, which is much higher than PVC $(0.4 \%)$ and ABS $(0.5 \%)$. The comparison of these three materials shows the effect of volume shrinkage on the part warpage. In addition, for comparison of the numerical results, the simulation and experiment are set with the same parameters. However, due to the different properties of each material, the molding process took the common value of every parameter for doing the simulation and the experiment. These parameters are mold temperature and melt temperature. The mold temperature was taken as $40^{\circ} \mathrm{C}$, $30{ }^{\circ} \mathrm{C}$, and $52{ }^{\circ} \mathrm{C}$ for PP, PVC, and ABS, respectively. The melt temperature was set at $200{ }^{\circ} \mathrm{C}, 200{ }^{\circ} \mathrm{C}$, and $240{ }^{\circ} \mathrm{C}$ for $\mathrm{PP}, \mathrm{PVC}$, and ABS, respectively.

Figure 5 shows the molded part with different thickness. These parts were used to measure the warpage with the measuring method, as shown in Figure 4. In this paper, by experiment, each case has 10 samples for measuring. Then, the average value was used for comparing and discussing. In addition, for a new case, the molding process continued for 10 cycles to ensure that the system reaches to the stable stage.

After the completion of the simulation and experiment, the result of warpage was collected and compared. These results were shown in Figure 6. According to this result, it 
was found that the warpage was significantly influenced by the thickness and the plastic material. In general, when the part thickness increases from $1.0 \mathrm{~mm}$ to $2.0 \mathrm{~mm}$, the warpage of PP material is higher than PVC and ABS. These results could be explained by the influence of the volume shrinkage. For PVC and ABS, the volume shrinkage is only $0.4 \%$ and $0.5 \%$, respectively. However, with PP material, the volume shrinkage is much higher, i.e., of the value of $2.5 \%$. Thus, after the completion of the molding process, the PP part has a larger shrinkage, and the result is that there is greater warpage in the PP part. This result is right when the part thickness increases from $1.0 \mathrm{~mm}$ to $2.0 \mathrm{~mm}$.

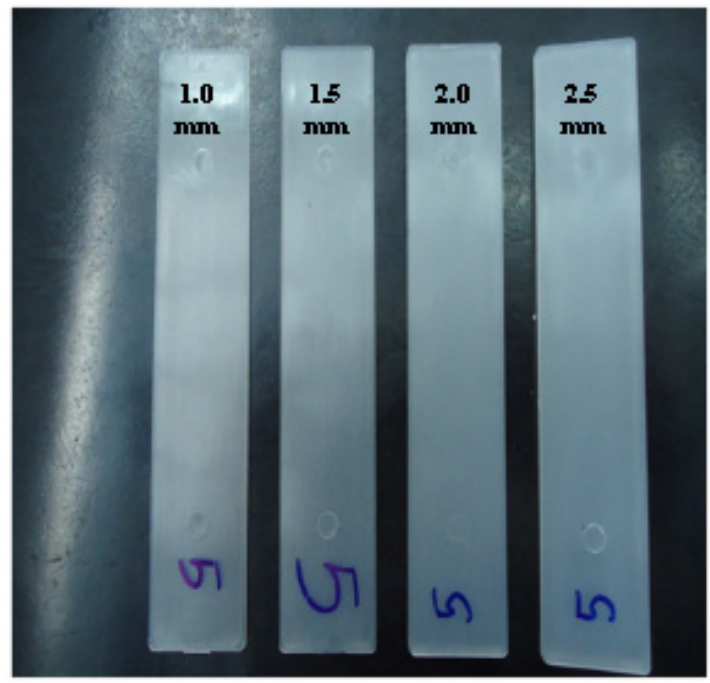

Figure 5. Injection molding part with PP material.

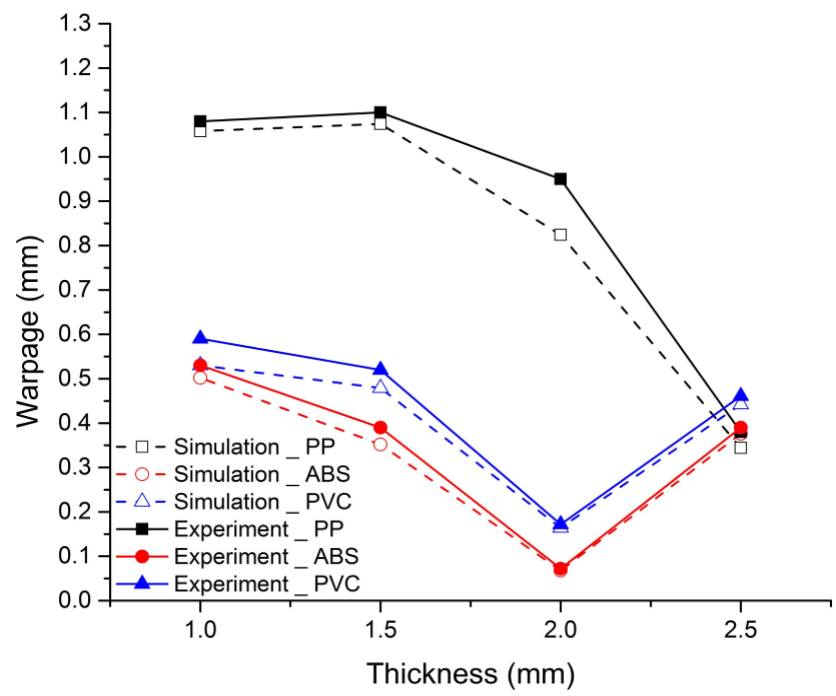

Figure 6. The variation of warpage with different part thickness and plastic materials.

In addition, in this range of part thickness, the thicker plate has a smaller warpage. This result could be explained by the rigidity of the plate. With the increase of the plate thickness, the rigidity improved. It means that, when the part was ejected from the mold, the rigidity will help to reduce the warpage. However, with the thickness of $2.5 \mathrm{~mm}$, all material types have the same warpage, it is approximately from $0.4 \mathrm{~mm}$ to $0.5 \mathrm{~mm}$. It is clearly seen that the warpage with the PP material still shows improvement, but the ABS and PVC was had the negative influence. For PP material, the warpage was reduced from $0.824 \mathrm{~mm}$ to $0.344 \mathrm{~mm}$. For ABS and PVC, the warpage was increased from $0.068 \mathrm{~mm}$ to $0.376 \mathrm{~mm}$ and $0.164 \mathrm{~mm}$ to $0.442 \mathrm{~mm}$, respectively. This result can be explained by the relation between critical rigidity and the shrinkage. For PP material in the case of $2.0 \mathrm{~mm}$, because the rigidity is not enough for reducing the shrinkage; therefore, with the thicker plate as the case of $2.5 \mathrm{~mm}$, the lower warpage will be obtained. In contrast, in ABS and PVC material, with the thickness of $2.0 \mathrm{~mm}$, the rigidity was enough to defend the shrinkage. So, with the thicker plate, or with the bigger plastic volume, the warpage will be created mainly by the unbalance shrinkage due to different temperatures between the core and cavity plate $[1,6$, and 8$]$, and between the inside and outside of the part $[5,7]$.

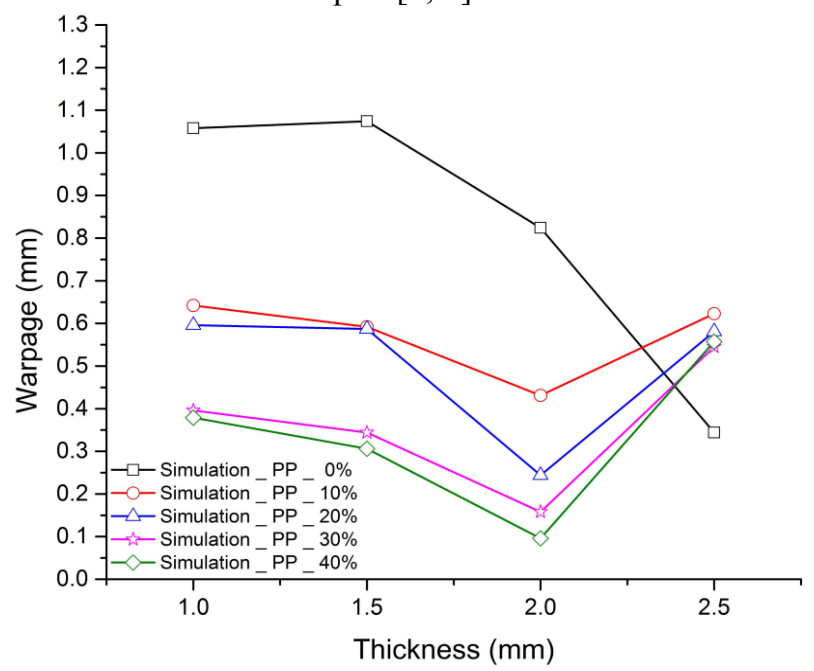

Figure 7. The variation of warpage with different part thickness and $\mathrm{CaCO}_{3}$ additive.

\subsection{Effect of $\mathrm{CaCO}_{3}$ on the Part Warpage with Different Part Thickness}

In this paper, for observing the effect of the additive material on the warpage, the $\mathrm{CaCO}_{3}$ was mixed with PP material under the weight ratio of $10 \%, 20 \%, 30 \%$, and $40 \%$. Then, the injection molding process was carried out. The same with above cases, for each case of $\mathrm{CaCO}_{3}$ ratio, the molding part was collected with 10 samples; then, the warpage was measured and compared. In this paper, the variation of warpage with different part thickness and $\mathrm{CaCO}_{3}$ ratios by simulation result is shown in Figure 7 and compared with experimentation result in Figure 8. In general, with the $\mathrm{CaCO}_{3}$ additive, the warpage was reduced greatly. More the $\mathrm{CaCO}_{3}$ ratio, the more reduction in warpage was observed. This result could be observed easily with the thickness of $1.0 \mathrm{~mm}, 1.5 \mathrm{~mm}$, and $2.0 \mathrm{~mm}$. However, in the case of $2.5 \mathrm{~mm}$, the $\mathrm{CaCO}_{3}$ has the negative effect on the part warpage when compared with the case of pure PP material. The positive of $\mathrm{CaCO}_{3}$ can be explained by the rigidity effect. 
More the $\mathrm{CaCO}_{3}$ ratio, the more is the rigidity that the part will have $[18,19]$. So, in this research, when the ratio of $\mathrm{CaCO}_{3}$ increases, the part rigidity improved; thus, this effect will help to reduce the warpage of the plate in the period of the part ejection in the injection molding process. In contrast, the $\mathrm{CaCO}_{3}$ additive also has some disadvantages in injection molding process, one of them is the reducing melt flow behavior. With the $\mathrm{CaCO}_{3}$ additive, the viscosity of plastic material increased; thus, the melt flow was harder in the filling step, especially in the packing step, also, the compensation was significantly reduced [20,21]. So, this is the main reason for the negative effect in the case of $2.5 \mathrm{~mm}$. Because for the thicker part more material is needed to be compensate for the packing step; thus, the $\mathrm{CaCO}_{3}$ additive was reduced this step. Hence, the result of the compensation for the in-mold shrinkage is not enough. And the final result is the raising of warpage in all case of $\mathrm{CaCO}_{3}$ additive. Even, in the case of $2.5 \mathrm{~mm}$ thickness, the pure PP material is the best case, due to the easy compensation in the packing step. In addition, with the comparison between simulation and experiment, as in Figure 8, it was found that the simulation and experiment agree well.
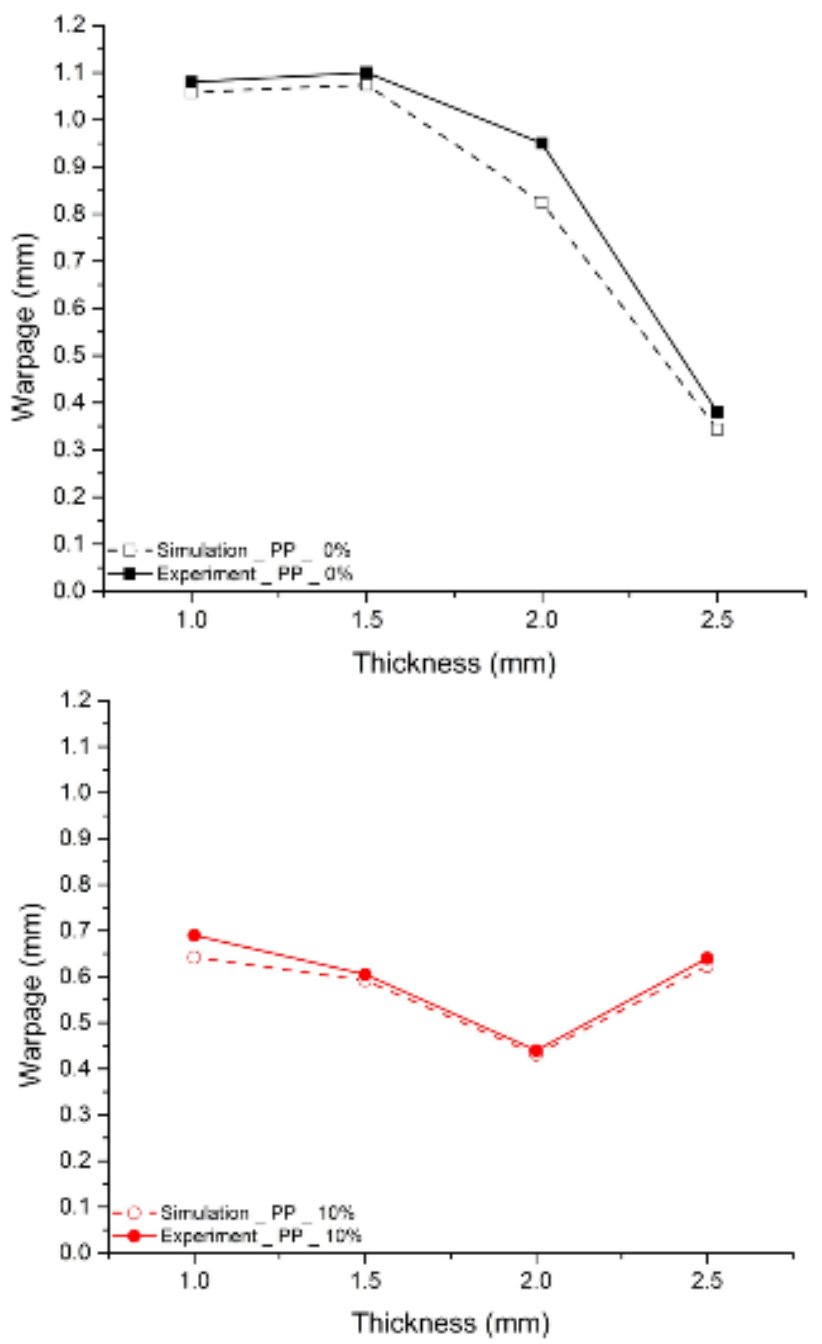
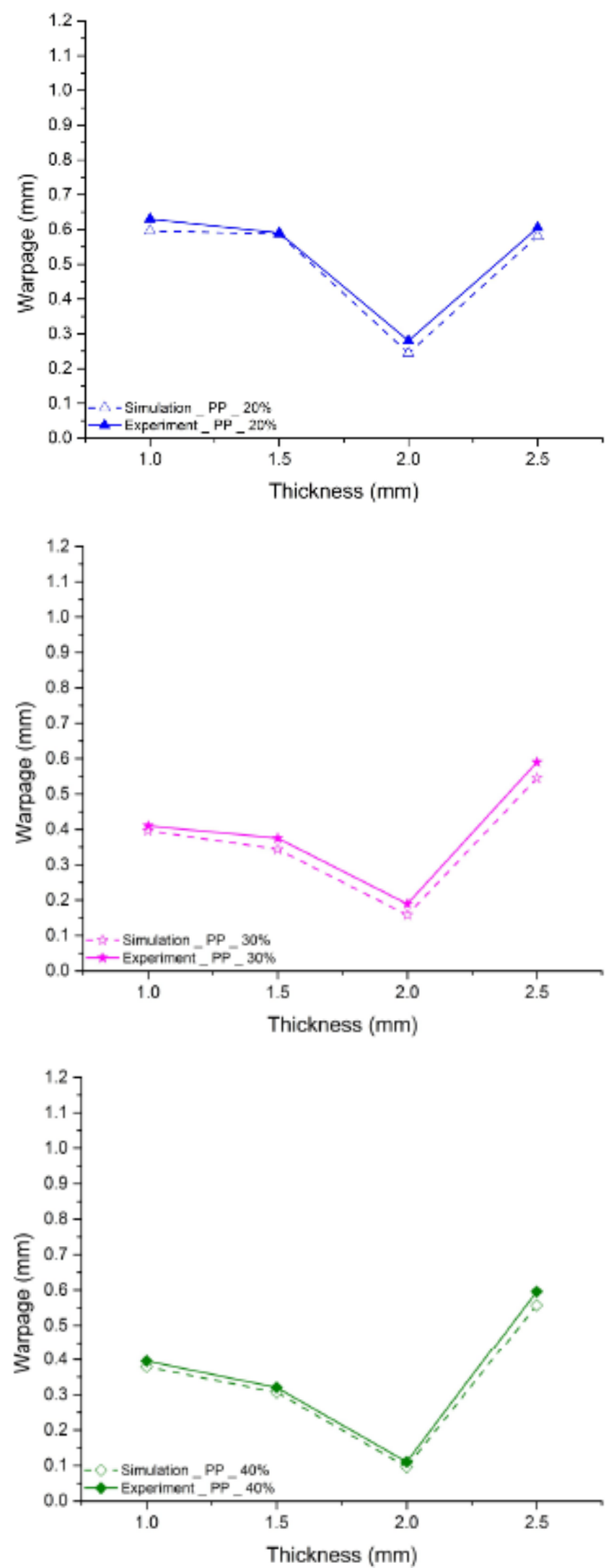

Figure 8. The comparison of simulation and experiment with different $\mathrm{CaCO}_{3}$ ratio and multi part thickness 


\section{Conclusions}

In this study, we perform research on the warpage of a rectangular plate with different part thickness, plastic materials, and $\mathrm{CaCO}_{3}$ ratios. By using both the simulation and experiment, the warpage was observed with these following conclusions:

- With the part thickness of $1.0 \mathrm{~mm}, 1.5 \mathrm{~mm}$, and 2.0 $\mathrm{mm}$, the ABS and PVC material have a smaller warpage due to the lower volume shrinkage. However, with the thickness of $2.5 \mathrm{~mm}$, the difference of warpage between these materials is not clear.

- With the ABS and PVC material, the warpage will reduce when the thickness increases from $1.0 \mathrm{~mm}$ to $2.0 \mathrm{~mm}$, however, due to the volume shrinkage and the freeze layer, it will increase when the thickness continuously rises to $2.5 \mathrm{~mm}$.

- $\quad$ By adding $\mathrm{CaCO}_{3}$ the PP material under different ratios, the warpage of the plate had been affected strongly. However, with the $2.5 \mathrm{~mm}$ thickness case, the warpage tend to increase as to the packing step needs more material for compensating the shrinkage.

\section{Acknowledgements}

This research was supported by University of Technical Education, Vietnam.

\section{REFERENCES}

[1] V.W.S. Yeung, K.H. Lau, Injection moulding, 'C-MOLD' CAE package, process parameter design and quality function deployment: A case study of intelligent materials processing, Elsevier, Journal of Materials Processing Technology, Vol.63, No. 1-3, 481-487.

[2] M. S. Huang, T. Y. Lin, Simulation of a regression-model and PCA based searching method developed for setting the robust injection molding parameters of multi-quality characteristics, Elsevier, International Journal of Heat and Mass Transfer, Vol.51, No. 25-26, 5828-5837.

[3] M. K. Karasu, M. Cakmakci, M. B. Cakiroglu, E. Ayva, N. D. Ortabas, Improvement of changeover times via Taguchi empowered SMED/case study on injection molding production, Elsevier, Measurement, Vol.47, 741-748.

[4] H. Oktem, T. Erzurumlu, I. Uzman, Application of Taguchi optimization technique in determining plastic injection molding process parameters for a thin-shell part, Elsevier, Materials \& Design, Vol.28, No.4, 1271-1278.

[5] S. Selvaraj, P. Venkataramaiah, Design and Fabrication of an Injection Moulding Tool for Cam Bush with Baffle Cooling Channel and Submarine Gate, Elsevier, Procedia Engineering, Vol.64, 1310-1319.

[1] H. Hassan, N. Regnier, G. Defaye, A 3D study on the effect of gate location on the cooling of polymer by injection molding, Elsevier, International Journal of Heat and Fluid Flow, Vol.30, No.6, 1218-1229.

[2] K. Yao, F. Gao, F. Allgöwer, Barrel temperature control during operation transition in injection molding, Elsevier, Control Engineering Practice, Vol.16, No.11, 1259-1264.

[3] S. J. Liu, , P. C. Su, Novel three-dimensional in-cavity transient temperature measurements in injection molding and fluid-assisted injection molding, Elsevier, Polymer Testing, Vol.28, No.1, 66-74.

[4] L. Liu, X. L. Ni, H. Q. Yin, X. H. Qu, Mouldability of various zirconia micro gears in micro powder injection moulding, Elsevier, Journal of the European Ceramic Society, Vol. 35, No.1, 171-177.

[5] M. Rahimi, M. Esfahanian, M. Moradi, Effect of reprocessing on shrinkage and mechanical properties of ABS and investigating the proper blend of virgin and recycled ABS in injection molding, Elsevier, Journal of Materials Processing Technology, Vol.214, No.11, 2359-2365.

[6] F. Yu, H. Deng, Q. Zhang, K. Wang, C. Zhang, F. Chen, Q. $\mathrm{Fu}$, Anisotropic multilayer conductive networks in carbon nanotubes filled polyethylene / polypropylene blends obtained through high speed thin wall injection molding, Elsevier, Polymer, Vol.54, No.23, 6425-6436.

[7] M.C. Song, , Z. Liu, M.J. Wang, T.M. Yu, D.Y. Zhao, Research on effects of injection process parameters on the molding process for ultra-thin wall plastic parts, Elsevier, Journal of Materials Processing Technology, Vol.187-188, 668-671.

[8] Y. K. Shen, J. J. Liu, C. T. Chang, C. Y. Chiu, Comparison of the results for semisolid and plastic injection molding process, Elsevier, International Communications in Heat and Mass Transfer, Vol.29, No.1, 97-105.

[9] F. Czerwinski, Size evolution of the unmelted phase during injection molding of semisolid magnesium alloys, Elsevier, Scripta Materialia, Vol.48, No.4, 327-331.

[10] C. Rauber , A. Lohmüller, S. Opel, R.F. Singer, Microstructure and mechanical properties of $\mathrm{SiC}$ particle reinforced magnesium composites processed by injection molding, Elsevier, Materials Science and Engineering: A, Vol.528, No.19-20, 6313-6323.

[11] E. Leroy, I. Petit, J. L. Audic, G. Colomines, , R. Deterre, Rheological characterization of a thermally unstable bioplastic in injection molding conditions, Elsevier, Polymer Degradation and Stability, Vol.97, No.10, 1915-1921.

[12] T.V. Zhil'tsova, M.S.A. Oliveira, J.A.F. Ferreira, Relative influence of injection molding processing conditions on HDPE acetabular cups dimensional stability, Elsevier, Journal of Materials Processing Technology, Vol.209, No.8, 3894-3904.

[13] S.M. Zebarjad, S.A. Sajjadi, On the strain rate sensitivity of HDPE/CaCO3 nano composites, Elsevier, Materials Science and Engineering: A, Vol.475, No.1-2, 365-367.

[14] M. W. L. Wilbrink, A. S. Argon, R. E. Cohen, M. Weinberg, Toughenability of Nylon- 6 with $\mathrm{CaCO} 3$ filler particles: new findings and general principles, Elsevier, Polymer, Vol. 42, No.26, 10155-10180.

[15] M. S. Huang, Cavity pressure based grey prediction of the 
filling-to-packing switchover point for injection molding, Elsevier, Journal of Materials Processing Technology, Vol.183, No.2-3, 419-424.

[16] S. Kitayama, S. Natsume, Multi-objective optimization of volume shrinkage and clamping force for plastic injection molding via sequential approximate optimization, Elsevier, Simulation Modelling Practice and Theory, Vol.48, 35-44.

[17] Online available from http://www.matweb.com 